\title{
Use of novel serum markers in clinical follow-up of Sertoli-Leydig cell tumours
}

\author{
Miriam Lenhard ${ }^{1, *}$, Caroline Kuemper ${ }^{1}$, Nina \\ Ditsch $^{1}$, Joachim Diebold ${ }^{2}$, Petra Stieber ${ }^{3}$, \\ Klaus Friese ${ }^{1}$ and Alexander Burges ${ }^{1}$ \\ ${ }^{1}$ Department of Obstetrics and Gynaecology, \\ Campus Grosshadern, Ludwig-Maximilians- \\ University, Munich, Germany \\ ${ }^{2}$ Department of Pathology, Ludwig-Maximilians- \\ University, Munich, Germany \\ ${ }^{3}$ Department of Clinical Chemistry, Ludwig- \\ Maximilians-University, Munich, Germany
}

\begin{abstract}
Background: Sertoli-Leydig cell tumours of the ovary account for only $0.2 \%$ of malignant ovarian tumours. Two-thirds of all patients become apparent due to the tumour's hormone production.

Methods: A 41-year-old patient (gravida 4, para 4) presented with dyspnoea, enlarged abdominal girth and melaena. Diagnostic imaging was suspicious for an ovarian cancer. The standard tumour marker for ovarian cancer (CA 125) was elevated to $984 \mathrm{U} / \mathrm{mL}$.

Results: Surgical exploration of the abdomen revealed a mouldering tumour of both adnexes extending to the level of the navel. Frozen sections showed an undifferentiated carcinoma of unknown origin. Radical surgery was performed. The final histological report described a malignant sex-cord stroma tumour, a Sertoli-Leydig cell tumour, emanating from both ovaries. Analysis of preoperative blood serum showed elevated levels of CYFRA 21-1 (10.4 ng/mL), neuron-specific enolase (36.2 ng/mL), oestradiol (485 pg/mL) and CA-125 (984 U/mL). Adjuvant chemotherapy and regional hyperthermia were performed due to the malignant potential and incomplete resection of the tumour.

Conclusions: Undifferentiated Sertoli-Leydig cell tumours show a poor clinical course. As only twothirds of patients with this rare disease present with elevated hormone levels, new markers deserve further investigation to offer more specific, individualised tumour monitoring.

Clin Chem Lab Med 2007;45:657-61.
\end{abstract}

*Corresponding author: Miriam Lenhard, MD, Department of Obstetrics and Gynaecology, Ludwig-MaximiliansUniversity Munich, Campus Grosshadern,

Marchioninistrasse 15, 80337 Munich, Germany

Phone: +49-89-7095-0, Fax: +49-89-7095-5844,

E-mail: miriam.lenhard@med.uni-muenchen.de
Keywords: ovarian malignancy; Sertoli-Leydig cell tumour; serum marker; sex-cord stromal tumour.

Sertoli-Leydig cell tumours are classified as sex-cord stromal tumours. They account for only $0.2 \%$ of malignant ovarian tumours and are often found unilaterally (1). Synonyms in the literature are arrhenoblastoma, androblastoma and gonadal stromal tumour of the android type. Most of these tumours are described in young adults and less than $10 \%$ occur prior to menarche or after menopause (2). Twothirds of all patients are diagnosed with this rare disease due to the tumour's hormone production (3).

A 41-year-old patient (IV gravida, IV para) presented with dyspnoea, enlarged abdominal girth and melaena. On physical examination, the abdomen was distended with a fluid wave. Auscultation showed decreased breath sounds over the basal lungs and dullness to percussion suspicious for pleural effusion. Gynaecological ultrasound and a computed tomography scan of the abdomen and lung revealed a more than $30-\mathrm{cm}$ ovarian tumour with peritoneal carcinosis and ascites. There was bilateral pleural effusion, but no signs of pulmonary nodules or other distant metastases. The standard tumour marker for ovarian cancer (CA 125) was elevated to $984 \mathrm{U} / \mathrm{mL}$ (Table 1). Preoperative colonoscopy did not show a pathologic finding except for polyposis. Bilateral chest tubes were placed to relieve the pleural effusion. Cytological analysis of the fluid was unremarkable. Surgical exploration revealed a mouldering, extremely soft tumour of the right adnex extending to the level of the navel and a 7-cm smooth tumour of the left adnex (Figure 1). Frozen sections were compatible with a poorly differentiated carcinoma of unknown primary origin. Hysterectomy, adnexectomy, appendectomy, omentectomy, peritonectomy of the lesser pelvis and anterior resection of the sigmoid colon and rectum were performed, reducing the size of the tumour to approximately $1 \mathrm{~cm}$, with a residual mass in the mesenterium of the small intestine. Due to low preoperative haemoglobin (78 g/L), a need for intraoperative blood transfusions and unclear histology, a lymphonodectomy was discounted. The final histologic report based on analysis of multiple tissue samples and results for immunohistochemical stains (including keratin, inhibin, calretinin, oestrogen and progesterone receptor) led to a diagnosis of a poorly differentiated Sertoli-Leydig cell tumour involving both ovaries. The tumour infiltrated the omentum, uterus, appendix and rectum. Post- 
Table 1 Serum markers for tumour monitoring.

\begin{tabular}{|c|c|c|c|}
\hline Serum marker & Preoperative & 9-month follow-up & Normal values \\
\hline \multicolumn{4}{|l|}{ Immunology } \\
\hline CYFRA 21-1, ng/mL & 10.4 & $<0.5$ & $<3.3$ \\
\hline $\mathrm{NSE}, \mathrm{ng} / \mathrm{mL}$ & 36.2 & 12.3 & $0-16.3$ \\
\hline CA $125, \mathrm{U} / \mathrm{mL}$ & 984 & 3.4 & $0.0-35.0$ \\
\hline CA $72-4, U / m L$ & 0.8 & 0.6 & $<7.0$ \\
\hline CEA, ng/mL & $<1.0$ & $<0.1$ & $<1.0$ \\
\hline AFP, ng/mL & 1.6 & 3.3 & $<15.0$ \\
\hline \multicolumn{4}{|l|}{ Endocrinology } \\
\hline HCG- $\beta, \mathrm{mIU} / \mathrm{mL}$ & $<2$ & $<2$ & $<2$ \\
\hline Oestradiol, pg/mL & 485 & 18.2 & $<10-300$ \\
\hline Testosterone, ng/mL & 0.2 & $<0.8$ & $<0.8 \mathrm{ng} / \mathrm{mL}$ \\
\hline
\end{tabular}

Serum markers analysed preoperatively and at clinical follow-up 9 months after primary diagnosis of the Sertoli-Leydig cell tumour. CYFRA, NSE, oestradiol and CA 125 seem to be suitable markers to monitor the clinical course of this patient's disease.

operative tumour stage was classified as pT3b, pNx, pMx, FIGO IIIB. Retrospective analysis of preoperative serum showed elevated levels of CYFRA 21-1 (10.4 ng/mL), neuron specific enolase (NSE; 36.2 $\mathrm{ng} / \mathrm{mL})$, oestradiol (485 pg/mL) and CA $125(984 \mathrm{U} / \mathrm{mL})$ (Table 1). Adjuvant chemotherapy with eight cycles of cisplatin $40 \mathrm{mg} / \mathrm{m}^{2} /$ day, etoposide $100 \mathrm{mg} / \mathrm{m}^{2} /$ day and ifosfamide $1800 \mathrm{mg} / \mathrm{m}^{2} /$ day for days $1-4$, in combination with regional hyperthermia, was chosen because of the malignant potential and incomplete resection of the tumour.

At 1-year follow-up, no recurrent abdominal mass could be identified either by physical examination or
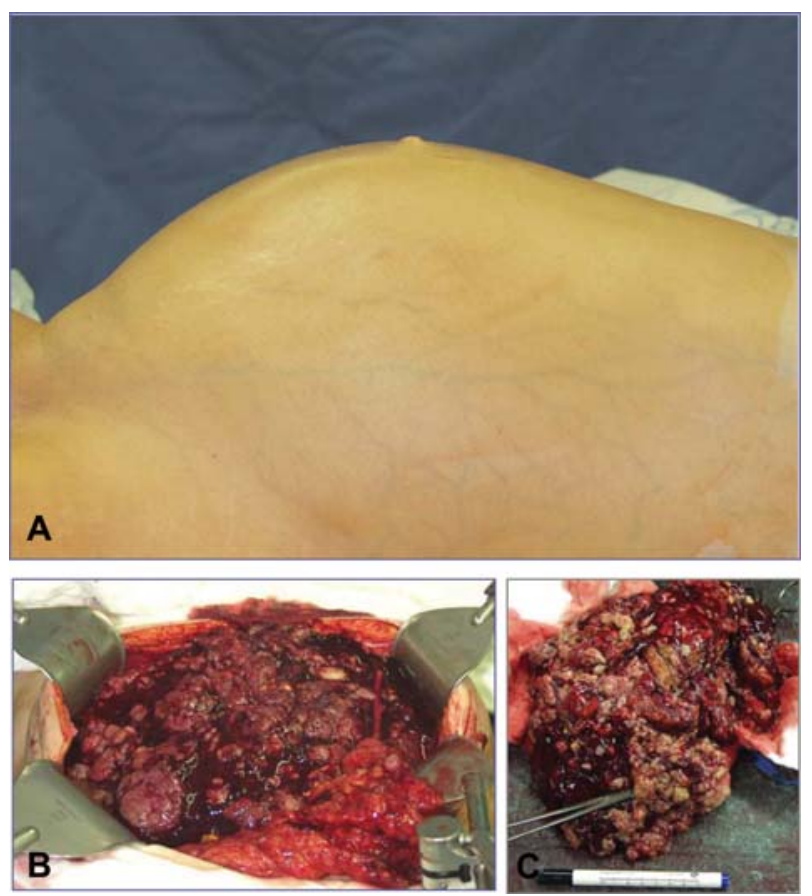

Figure 1 Clinical presentation and macroscopic tumour appearance.

(A) Preoperative photograph of the patient: the abdomen is distended compared to the cachectic body. (B) The intraoperative situs shows the abdomen filled with a mouldering tumour and bloody ascites. (C) The right adnex consists of a more than $30-\mathrm{cm}$ crumbly tumour: frozen section shows a poorly differentiated carcinoma of unknown primary origin. by a computed tomography scan of the abdomen. Serum markers were analysed on a 3-monthly base, and so far show no signs of recurrence.

Sertoli-Leydig cell tumours account for $0.2 \%$ of ovarian neoplasms (1). They are classified as one of five histopathological types: well, intermediately or poorly differentiated, with a retiform component or with heterologous elements (gastrointestinal-type epithelium, hepatocytes, skeletal muscle or cartilage) (4). They consist of Sertoli and Leydig cells in varying proportions and varying differentiation. Poorly differentiated Sertoli-Leydig cell tumours are sarcomatoid in appearance (5). Sertoli and Leydig cells can stain positive for testosterone and oestradiol (6). Areas with Sertoli tumour cells are positive for vimentin and may express keratins, but are typically negative for epithelial membrane antigen (EMA), placenta-like alkaline phosphatase (PLAP), carcinoembryonic antigen (CEA), CA 19.9, CA 125 and S-100 protein (7). Leydig cells are predominantly positive for vimentin and $\alpha$-inhibin and stain negative for keratins (8). In our case, the tumour cells expressed keratin (C), inhibin (D) and calretinin (E), as well as oestrogen receptor (F) and progesterone receptor (G) (Figure 2).

Approximately $70 \%-75 \%$ of Sertoli-Leydig cell tumours occur in young adults, with a mean age of 25 years at primary diagnosis (2). There are six case reports in the literature describing this rare disease in postmenopausal women (9-14). Commonly, SertoliLeydig cell tumours are detected at an early stage ( $80 \%$ stage la). Only less than $3 \%$ have spread beyond the ovary (15). Metastases are predominantly described in the omentum, the abdominal lymph nodes and the liver. Nonetheless, one case of a metastasis in the frontal sinus has been reported (16). Hardly ever are both ovaries involved. A review of 207 cases showed an incidence of $1.4 \%$ of bilateral Sertoli-Leydig cell tumour (17). In this review, all welldifferentiated tumours proved benign (18), whereas $11 \%$ of intermediately and $58 \%$ of poorly differentiated tumours showed malignant behaviour. In the same collective, malignant behaviour was observed in $19 \%$ of patients with heterologous tumour elements (17). Moderately and undifferentiated tumours with malignant potential show a significantly poorer 



Figure 2 Tumour histology.

Low-power view of the Sertoli-Leydig cell tumour: (A) right and (B) left ovary (haematoxylin and eosin staining, original magnification $2.5 \times$ ). Immunohistochemistry reveals expression of (C) keratin, (D) inhibin (particularly in Leydig cells), (E) calretinin (particularly in the poorly differentiated Sertoli component), (F) oestrogen receptor and (G) progesterone receptor (magnification $40 \times$ ).

clinical course compared to well-differentiated tumours. Nonetheless, an analysis of 64 intermediate and poorly differentiated Sertoli-Leydig cell tumours described a 5- and 10-year survival rate of $92 \%$ (19). If recurrence occurs, it mainly appears within the first year after primary diagnosis, typically in the peritoneal space or retroperitoneal lymph nodes. A retrospective study by Chan et al. analysed prognostic factors responsible for survival in sex-cord stromal tumours. They reported that age $<50$ years, small tumour size and absence of residual disease were important predictors of improved survival (20).

The majority of patients become apparent because of abdominal enlargement or pain caused by the enormous size of the tumour $(13,15)$, which is an average of $5-20 \mathrm{~cm}$ in diameter. Approximately twothirds of patients present with elevated hormone levels. Typical signs of elevated oestrogen or testosterone levels are mild virilisation or irregular periods. In this context, $35 \%$ of all women show symptoms of androgen excess indicated by acne, temporal balding, progressive masculinisation of veins, deepening of the voice, disappearance of female body contours or enlargement of the clitoris (15). These patients typi- cally have elevated testosterone levels. The endometrium can be affected by oestrogen synthesis induced by peripheral aromatase or by direct oestrogen production by the tumour.

In the case presented here, there were no obvious clinical signs of elevated hormone levels. Asked specifically, the patient mentioned period disorders (such as menorrhoea) that could be explained by the high oestrogen production by the tumour.

To detect tumour markers other than the known standard for ovarian cancer (CA 125), we performed detailed serum analysis, which revealed elevated oestrogen and normal testosterone levels, as well as elevated levels of NSE and CYFRA, which, to the best of our knowledge, have so far not been found in SertoliLeydig cell tumour patients. CYFRA is known to be elevated in ovarian malignancies (21). NSE is present in all neurons and is therefore recognised as a molecular marker of neuroendocrine tissue (22). In the literature, NSE has been described in the context of mature teratomas, immature teratomas, and dysgerminomas (23). These tumour markers may also be useful in our patient's clinical follow-up and offer more specific, individualised monitoring. 
Treatment recommended for Sertoli-Leydig cell tumours varies with differentiation, tumour stage and patient age. Treatment modalities discussed are often controversial, as only a few studies have investigated this rare disease. Definitive operative staging should be performed in all Sertoli-Leydig cell tumours showing intermediate and low differentiation, including multiple biopsies and tissue from the omentum, as well as evaluation of the pelvic and para-aortal lymph nodes. Resection of normal lymph nodes is controversial. If the tumour is highly differentiated and if there is no sign of spread beyond the ovary involved in a young woman, unilateral adnexectomy might be justified. In our case the patient presented with a tumour of low differentiation at an advanced stage with unknown primary origin. Therefore, surgery involving hysterectomy, adnexectomy, appendectomy, omentectomy, peritonectomy of the lesser pelvis and anterior resection of the sigmoid colon and rectum was performed to reduce the tumour mass.

The benefit of adjuvant radio- or chemotherapy is not proven, but may be considered in cases of incomplete tumour resection (24). Because of the low differentiation of the tumour, the residual tumour mass and the advanced stage, chemotherapy with cisplatin, etoposide and ifosfamide combined with hyperthermia according to the MAKEI protocol was chosen for this patient. Chemotherapy regimes with cyclophosphamide in combination with either cisplatin and doxorubicin (25) or vincristine and actinomycin D (26) have also proven useful in individual cases. Hormonal manipulation has been even used as a therapeutic approach (27).

This case of a bilateral tumour in a perimenopausal woman demonstrates different rare aspects for Sertoli-Leydig cell tumours. Unlike most cases, this patient showed normal androgen but elevated oestrogen serum levels. We also found elevated serum levels of NSE and CYFRA, which, to the best of our knowledge, is a new finding in the context of SertoliLeydig cell tumours. As only two-thirds of patients with this rare disease present with elevated hormone levels, these two markers deserve further investigation, because they may be suitable for more specific, individualised tumour monitoring.

\section{References}

1. Young RH, Dudley AG, Scully RE. Granulosa cell, SertoliLeydig cell, and unclassified sex cord-stromal tumors associated with pregnancy: a clinicopathological analysis of thirty-six cases. Gynecol Oncol 1984;18:181-205.

2. Roth LM, Anderson MC, Govan AD, Langley FA, Gowing NF, Woodcock AS. Sertoli-Leydig cell tumors: a clinicopathologic study of 34 cases. Cancer 1981;48:187-97.

3. O'Hern TM, Neubecker RD. Arrhenoblastoma. Obstet Gynecol 1962;19:758-70.

4. Young RH. Sertoli-Leydig cell tumors of the ovary: review with emphasis on historical aspects and unusual variants. Int J Gynecol Pathol 1993;12:141-7.

5. Ching B, Klink A, Wang L. Pathologic quiz case: a 22-yearold woman with a large right adnexal mass. Poorly differentiated Sertoli-Leydig cell tumor of the right ovary with retiform differentiation and heterologous elements (mucinous components). Arch Pathol Lab Med 2004; 128:e93-5.

6. Kurman RJ, Andrade D, Goebelsmann U, Taylor CR. An immunohistological study of steroid localization in Sertoli-Leydig tumors of the ovary and testis. Cancer 1978;42:1772-83.

7. Costa MJ, Morris RJ, Wilson R, Judd R. Utility of immunohistochemistry in distinguishing ovarian Sertoli-stromal cell tumors from carcinosarcomas. Hum Pathol 1992; $23: 7 \overline{87-97}$

8. Costa MJ, Ames PF, Walls J, Roth LM. Inhibin immunohistochemistry applied to ovarian neoplasms: a novel, effective, diagnostic tool. Hum Pathol 1997;28:1247-54.

9. Caringella A, Loizzi V, Resta L, Ferreri R, Loverro G. A case of Sertoli-Leydig cell tumor in a postmenopausal woman. Int J Gynecol Cancer 2006;16:435-8.

10. Gheorghisan-Galateanu A, Fica S, Terzea DC, Caragheorgheopol A, Horhoianu V. Sertoli-Leydig cell tumor - a rare androgen secreting ovarian tumor in postmenopausal women. Case report and review of literature. J Cell Mol Med 2003;7:461-71.

11. Hansen TP, Sorensen B. Sertoli-Leydig cell tumour of the ovary - a rare cause of virilization after menopause. Apmis 1993;101:663-6.

12. Tampakoudis $P$, Zafrakas $M$, Kostopoulou $E$, Dragoumis K, Tsalikis T, Bontis J. Ovarian Sertoli-Leydig cell tumor with coexisting vaginal angiomyxoma: case report and review of the literature. Eur J Gynaecol Oncol 2004; 25:116-8

13. Dhont M, Vandekerckhove F, Praet M, Vanluchene $E$, Vandekerckhove D. A feminizing Sertoli-Leydig cell tumour in a postmenopausal woman. Case report. $\mathrm{Br} \mathrm{J}$ Obstet Gynaecol 1986;93:1171-5.

14. Clinton CW, Rogaly E, Bernstein J. Leydig-Sertoli cell tumour in the postmenopausal female. A case report. S Afr Med J 1981;60:434-5.

15. Lantzsch T, Stoerer S, Lawrenz K, Buchmann J, Strauss HG, Koelbl H. Sertoli-Leydig cell tumor. Arch Gynecol Obstet 2001;264:206-8.

16. Campisi P, Cheski P. Metastatic Sertoli-Leydig cell ovarian cancer manifested as a frontal sinus mass. J Otolaryngol 1998;27:361-2.

17. Young RH, Scully RE. Ovarian Sertoli-Leydig cell tumors. A clinicopathological analysis of 207 cases. Am J Surg Pathol 1985;9:543-69.

18. Young RH, Scully RE. Well-differentiated ovarian SertoliLeydig cell tumors: a clinicopathological analysis of 23 cases. Int J Gynecol Pathol 1984;3:277-90.

19. Zaloudek C, Norris HJ. Sertoli-Leydig tumors of the ovary. A clinicopathologic study of 64 intermediate and poorly differentiated neoplasms. Am J Surg Pathol 1984:8:405-18.

20. Chan JK, Zhang M, Kaleb V, Loizzi V, Benjamin J, Vasilev $\mathrm{S}$, et al. Prognostic factors responsible for survival in sex cord stromal tumors of the ovary - a multivariate analysis. Gynecol Oncol 2005;96:204-9.

21. Gadducci A, Ferdeghini M, Cosio S, Fanucchi A, Cristofani R, Genazzani AR. The clinical relevance of serum CYFRA 21-1 assay in patients with ovarian cancer. Int $\mathrm{J}$ Gynecol Cancer 2001;11:277-82.

22. Prinz RA, Marangos PJ. Use of neuron-specific enolase as a serum marker for neuroendocrine neoplasms. Surgery 1982;92:887-9.

23. Yoshida M, Koshiyama M, Konishi M, Fujii H, Nanno $H$, Hayashi $\mathrm{M}$, et al. Ovarian dysgerminoma showing high serum levels and positive immunostaining of placental alkaline phosphatase and neuron-specific enolase associated with elevation of serum prolactin level. Eur J Obstet Gynecol Reprod Biol 1998;81:123-8.

24. Gershenson DM, Morris M, Burke TW, Levenback C, Matthews CM, Wharton JT. Treatment of poor-progno- 
sis sex cord-stromal tumors of the ovary with the combination of bleomycin, etoposide, and cisplatin. Obstet Gynecol 1996;87:527-31.

25. Gershenson DM, Copeland LJ, Kavanagh JJ, Stringer CA, Saul PB, Wharton JT. Treatment of metastatic stromal tumors of the ovary with cisplatin, doxorubicin, and cyclophosphamide. Obstet Gynecol 1987;70:765-9.
26. Schwartz PE, Smith JP. Treatment of ovarian stromal tumors. Am J Obstet Gynecol 1976;125:402-11.

27. Emons G, Schally AV. The use of luteinizing hormone releasing hormone agonists and antagonists in gynaecological cancers. Hum Reprod 1994;9:1364-79.

Received December 19, 2006, accepted February 20, 2007 